\title{
Change of Physical State of Agrosoils under Irrigation
}

\author{
Tatarintsev V.L. \\ Altay State Agricultural University \\ FSBEI HE Altai SAU \\ Barnaul, Russian Federation \\ kafzem@bk.ru
}

\author{
Tatarintsev L.M. \\ Altay State Agricultural University \\ FSBEI HE Altai SAU \\ Barnaul, Russian Federation \\ kafzem@bk.ru
}

\author{
Myagkiy P.A. \\ Altay State Agricultural University \\ FSBEI HE Altai SAU \\ Barnaul, Russian Federation \\ zemkaf2010@lenta.ru
}

\begin{abstract}
The physical condition of agricultural soils is the main characteristic of their stability in relation to anthropogenic activities. One of the main reasons that have a serious impact on the physical condition of agricultural soils and are formed on their agrocenosis is their artificial irrigation. The authors of the scientific work examined in the field the physical condition of variation depending on the irrigation of saline or freshwater agrosoils in the South of West Siberia. The reason for the transformation of the physical condition of irrigated chestnuts agrosoils is the change process due to the sulphate irrigation waters. The transformation of the physical condition of nonmineral irrigation waters $(0.3-0.4 \mathrm{~g} / \mathrm{l}$ of salts) was studied using ordinary and leached chernozem. The additional moistening of agrosoils appeared in an increase in the power of the humus horizon, reduction in the depth of the carbonate horizon and appearance of a micellar form of carbonates. On the grounds of investigated transformation of the studied physical condition of irrigated agrosoils, the measures of meliorative and agrotechnical nature are offered, which will allow one to receive on the average 60-65 t/ha of green mass of corn, 10-13 t/ha of Lucerne hay without essential decrease in fertility of irrigated agrosoils, that will influence an increase of food safety of the region.
\end{abstract}

Keywords-Physical condition, agricultural soils, South of Western Siberia, irrigation, salt accumulation, transformation, food security.

\section{INTRODUCTION}

The current physical condition of the main arable soils in the South of Western Siberia is inherited from the preagricultural stage of evolution of zonal soils, when the decisive role in soil formation belonged to the bioclimatic factor. In turn, the nature of change of a physical condition of the irrigated agrosoils is directly dependent on the quality of irrigation water as well as irrigation duration.

The main objective of the present study was to examine the influence of irrigation in the field (the mineralized and fresh waters), to change properties of a solid phase of chernozems and chestnut soils used in agriculture on the territory in the south of Western Siberia. The research problems are to analyse the reasons and speed of change of physical properties of southern chernozems and ordinary chernozems and chestnut agrosoils; to study influence of the mineralized and non-mineralized irrigation waters; to show possibilities of further meliorative development of the territory to increase food security of the region

\section{LITERATURE REVIEW}

The considerable number of works is devoted to a problem of irrigation of chernozems and chestnut soils ([1, 2, 3, 4, 5, 6, $7,8,9,10]$. In recent years, this problem has become relevant for Western Siberia where there are many irrigated areas. Therefore the objective understanding of genesis of irrigation agrosoils is necessary.

Research results showed $[10,11,12,13,14,15,16,17,18$, $19,20,21]$ that development of chernozems under irrigation effect has a number of common patterns.

Common patterns include:

1) change of non-washing water regime type to irrigational-washing;

2) strengthening of microbiological activity, speed and capacity of biological substances circulation and energy;

3) strengthening of intensity of mineralization processes and transformation of organic substance, substances migration;

4) reduction of cationic exchange capacity, cationic structure transformation and increase in average of soil solution reaction.

Features of change of a physical state are shown at the level of the absolute values characterizing agrosoils and in intensity of their transformation. 


\section{RESEARCH METHODOLOGY}

The authors of the research widely applied the system approach. Agrosoils in this approach represent a difficult system with an infinitely big variety of the internal and external functional relations having a very complex multilevel structural organization. Each level of the agrosoils organization is considered as a subsystem. In addition to the system analysis, the authors applied methods of statistical analysis and synthesis, comparative-historical analysis and datalogical analysis. The method of soil-regime observations was applied directly in field research.

\section{RESULTS}

Soils irrigation with mineralized waters are accompanied by secondary salt accumulation. Poorly mineralized underground waters are used during irrigation of chestnut soils and chernozems. They have a hydrocarbonate-sulphate or sulphate composition - by anion, sodium-magnesium (magnesium-sodium) with the participation of calcium - by cations. All waters have alkalinity $(\mathrm{pH}=7.2-8.5)$. With an existing pulsating process of salt accumulation, if there is no connection to groundwater, chestnut non-saline soils will turn into weakly saline irrigation after 50 years. When a groundwater level rises, a secondary salinization of soil occurs after 10 years (sometimes faster), i.e. 5 times faster than when there is no connection to groundwater.

Sulphate water irrigation leads to reduction of oxidationreduction potential (ORP), increase of alkalinity, growth of humus and iron mobility in soils. Against the background of these processes, there is their alkalinization and alkalization.

The alkalization of chestnut medium loamy soils causes a breakdown in the structural bonds between soil particles and formation of micro- and macroaggregates. The results of table 1 clearly demonstrate an assumption. In irrigated chestnut soils (especially for a long time), there is a decrease in silt and physical clay, which is detected by particle size analysis, an increase in micro- and macro-aggregates. At the same time, aggregates with a new quality that are different from the quality of non-irrigated soil aggregates are formed. The newly formed soils are distinguished by high mechanical strength, density, low porosity and high water resistance. Micromorphological studies show that in this case the microcomposition of soil becomes compact, the structure of the pore space is simplified, which indicates the dissolution of irrigated chestnut soil. Colloid-chemical analysis indicates that the newly created structure is cemented with a ferrous clay material. Moreover, the longer the irrigation, the higher the mechanical and water resistance of the aggregates, the density of soil.

Changes at the aggregate level of the soil organization are accompanied by transformation of physical parameters of soil: the density of addition increases, the least moisture capacity increases, the total porosity decreases, aeration, reserve water compatibility. Even adsorption capacity of irrigated chestnut soils is reduced due to a decrease in the specific surface due to the formation of micro- and macro-aggregates.

TABLE 1. CHANGE OF A PHYSICAL CONDITION OF CHESTNUT SOILS OF THE DRY STEPPE UNDER THE INFLUENCE OF IRRIGATION

\begin{tabular}{|c|c|c|c|c|c|c|c|c|c|c|c|}
\hline \multirow{2}{*}{ Horizon } & \multicolumn{2}{|c|}{$\begin{array}{c}\text { particle content, } \\
\% ;\end{array}$} & \multirow{2}{*}{$\begin{array}{c}\text { True } \\
\text { Microag } \\
\text { gregates } \\
\mathbf{0 , 2 5 - 0 , 0 1} \\
\text { mm, \% }\end{array}$} & \multirow{2}{*}{$\begin{array}{l}\text { Water- } \\
\text { resistant } \\
\text { units 5- } \\
0,25 \text { mm, } \\
\%\end{array}$} & \multirow{2}{*}{$\begin{array}{r}\begin{array}{c}\text { Densit } \\
\text { y Soil }\end{array} \\
g / s \\
\end{array}$} & \multirow{2}{*}{$\begin{array}{c}\text { Densit } \\
\text { y of } \\
\text { solids } \\
\text { phase } \\
\boldsymbol{t}^{3}\end{array}$} & \multicolumn{2}{|c|}{ porosity, \% } & \multirow{2}{*}{$\begin{array}{c}\text { Reserve } \\
\text { water } \\
\text { capacity, } \\
\%\end{array}$} & \multicolumn{2}{|c|}{$\begin{array}{c}\text { water properties } \\
\% \text { weight }\end{array}$} \\
\hline & $\begin{array}{c}<0,001 \\
\mathrm{~mm}\end{array}$ & $\begin{array}{c}<0,01 \\
\mathrm{~mm}\end{array}$ & & & & & Total & $\begin{array}{c}\text { Aeratio } \\
\boldsymbol{n} \boldsymbol{H B}\end{array}$ & & B3 & $H B$ \\
\hline \multicolumn{12}{|c|}{ Not irrigated } \\
\hline $\mathrm{A}_{\text {пах }}$ & 19,9 & 36,2 & 23,0 & 8,1 & 1,29 & 2,60 & 50,4 & 21,3 & 6,3 & 8,0 & 29,1 \\
\hline $\mathrm{AB}$ & 17,1 & 34,5 & 25,9 & 12,7 & 1,34 & 2,60 & 48,5 & 23,8 & 8,6 & 11,7 & 24,7 \\
\hline $\mathrm{B}$ & 10,5 & 33,3 & 20,0 & - & 1,49 & 2,67 & 44,2 & 17,9 & 2,9 & 11,4 & 26,3 \\
\hline $\mathrm{BC}$ & 14,8 & 35,7 & 19,7 & - & 1,69 & 2,64 & 36,0 & - & - & 8,2 & - \\
\hline $\mathrm{C}$ & 10,5 & 34,4 & 18,2 & - & 1,69 & 2,68 & 36,8 & - & - & 7,3 & - \\
\hline \multicolumn{12}{|c|}{ Iirrigated, 5 years } \\
\hline $\mathrm{A}_{\text {пах }}$ & 11,7 & 34,2 & 25,4 & 17,3 & 1,42 & 2,66 & 46,6 & 17,9 & 2,9 & 7,7 & 28,7 \\
\hline $\mathrm{AB}$ & 16,6 & 34,6 & 26,8 & 14,7 & 1,54 & 2,68 & 42,5 & 13,5 & 0 & 8,5 & 29,0 \\
\hline $\mathrm{B}$ & 16,6 & 36,1 & 22,7 & 14,5 & 1,63 & 2,68 & 39,2 & 10,0 & 0 & 7,8 & 29,2 \\
\hline $\mathrm{BC}$ & 23,9 & 34,5 & 21,8 & - & 1,62 & 2,70 & 40,0 & 9,7 & 0 & 7,7 & 30,3 \\
\hline $\mathrm{C}$ & 10,4 & 34,6 & 20,2 & - & 1,64 & 2,71 & 39,6 & 15,2 & 0,2 & 9,4 & 14,3 \\
\hline \multicolumn{12}{|c|}{ Iirrigated, 10 years } \\
\hline $\mathrm{A}_{\text {пах }}$ & 8,1 & 33,7 & 27,3 & 38,9 & 1,38 & 2,62 & 47,3 & 21,0 & 6,1 & 6,0 & 34,1 \\
\hline $\mathrm{AB}$ & 13,6 & 33,0 & 28,9 & 28,1 & 1,45 & 2,62 & 44,6 & 17,0 & 2,0 & 6,4 & 29,3 \\
\hline $\mathrm{B}$ & 12,8 & 35,6 & 27,7 & - & 1,60 & 2,66 & 39,8 & 18,1 & 0 & 7,4 & 24,3 \\
\hline $\mathrm{BC}$ & 14,1 & 34,6 & 21,9 & - & 1,63 & 2,68 & 39,2 & 9,8 & 0 & 4,4 & 23,4 \\
\hline $\mathrm{C}$ & 10,1 & 32,5 & 21,0 & - & 1,67 & 2,67 & 37,4 & 8,3 & 0 & 3,3 & 18,1 \\
\hline
\end{tabular}

The transformation of physical state of irrigated chestnut agrosoils is change in the soil-forming process due to the irrigation with sulphate waters. Contrast ORP determines the mobility of iron, humus, calcium. These phenomena contribute to solid phase cementing with free iron-containing organo-mineral complexes. Aggregation of soil solution, which we had to observe in certain periods of time after irrigation with sulphate-sodium waters, apparently contributed to the gluing of the aggregates. 
The transformation of physical state during irrigation with non-mineralized waters $(0.3-0.4 \mathrm{~g} / 1$ of salts) was studied on ordinary and leached chernozems. Studies were carried out on chernozems; the duration of irrigation is 10,15 and 30 years. Irrigated chernozems were used in vegetable crop rotation. Irrigation rates ranged from 1500 to $3000 \mathrm{~m}^{3} / \mathrm{ha}$.

Additional moistening of agrosoil manifested itself in an increase in the thickness of the humus horizon, a decrease in the depth of the carbonate horizon, the absence of a whiteeyed eye and the appearance of the mycelial form of carbonates.
Data from physico-chemical and chemical analyzes record the migration of humus, calcium, magnesium, sodium, nutrients, changes in the qualitative composition of humus, water-soluble salts, and a decrease in $\mathrm{pH}$.

A more contrasting change in the qualitative attributes of chernozems is seen in the micro level. In irrigated (especially the 30-year term) chernozems, micro- and macro-aggregation is less pronounced, the anisotropy of the microstructure increases, thin intra- and inter-aggregate porosity disappears, pores and cracks of packing of large angular aggregates appear.

TABLE 2/ CHANGES IN THE PHYSICAL CONDITION OF LEACHED CHERNOZEM OF KOLOCHNAYA STEPPES UNDER THE INFLUENCE OF IRRIGATION

\begin{tabular}{|c|c|c|c|c|c|c|c|c|c|c|c|}
\hline \multirow{2}{*}{ Horizon } & \multicolumn{2}{|c|}{$\begin{array}{c}\text { particle content, } \\
\qquad \% ;\end{array}$} & \multirow{2}{*}{$\begin{array}{c}\text { True } \\
\text { Microag } \\
\text { gregates } \\
\mathbf{0 , 2 5 - 0 , 0 1} \\
\mathbf{m m}, \%\end{array}$} & \multirow{2}{*}{$\begin{array}{c}\text { Water- } \\
\text { resistant } \\
\text { units } \\
\mathbf{5 - 0 , 2 5} \\
\text { mm, \% }\end{array}$} & \multirow{2}{*}{$\begin{array}{c}\begin{array}{c}\text { Den- } \\
\text { sity } \\
\text { soil }\end{array} \\
\quad g /\end{array}$} & \multirow{2}{*}{$\begin{array}{l}\begin{array}{c}\text { Densit } \\
\text { y of } \\
\text { solids } \\
\text { phase }\end{array} \\
3\end{array}$} & \multicolumn{2}{|c|}{ porosity, \% } & \multirow{2}{*}{$\begin{array}{c}\text { Reserve } \\
\text { water } \\
\text { capacity, } \\
\%\end{array}$} & \multicolumn{2}{|c|}{$\begin{array}{c}\text { water properties, } \\
\text { weight } \%\end{array}$} \\
\hline & $\begin{array}{c}<0,001 \\
\mathrm{~mm}\end{array}$ & $\begin{array}{l}<0,01 \\
m m\end{array}$ & & & & & Total & $\begin{array}{c}\text { Aera- } \\
\text { tion } \\
H B\end{array}$ & & $B 3$ & $H B$ \\
\hline \multicolumn{12}{|c|}{ Not irrigated } \\
\hline $\mathrm{A}_{\max }$ & 15,0 & 39,8 & 28,6 & 17,1 & 1,25 & 2,61 & 54,0 & 17,6 & 2,6 & 9,5 & 30,4 \\
\hline $\mathrm{AB}$ & 20,6 & 42,5 & 29,8 & 23,1 & 1,16 & 2,62 & 55,7 & 24,1 & 9,1 & 9,3 & 27,2 \\
\hline $\mathrm{B}$ & 21,3 & 40,3 & 26,3 & 43,5 & 1,33 & 2,68 & 50,0 & 22,3 & 7,3 & 8,7 & 20,7 \\
\hline $\mathrm{BC}$ & 17,9 & 37,5 & 27,4 & - & 1,40 & 2,74 & 48,9 & 22,9 & 7,9 & 8,4 & 18,6 \\
\hline $\mathrm{C}$ & 17,0 & 35,7 & 29,0 & 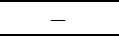 & 1,43 & 2,75 & 48,0 & 24,1 & 9,1 & 8,1 & 16,9 \\
\hline \multicolumn{12}{|c|}{ Iirrigated, 10 years } \\
\hline $\mathrm{A}_{\text {пах }}$ & 14,2 & 39,2 & 27,8 & 17,2 & 1,26 & 2,60 & 51,5 & 14,0 & 0 & 9,3 & 29,8 \\
\hline $\mathrm{AB}$ & 21,4 & 43,6 & 31,9 & 13,3 & 1,19 & 2,63 & 54,7 & 28,6 & 13,6 & 9,3 & 22,0 \\
\hline $\mathrm{B}$ & 18,6 & 39,8 & 24,6 & 86,6 & 1,30 & 2,67 & 51,3 & 25,9 & 10,9 & 8,9 & 19,4 \\
\hline $\mathrm{BC}$ & 18,8 & 38,2 & 25,6 & - & 1,45 & 2,71 & 46,5 & 19,8 & 4,8 & 8,5 & 18,4 \\
\hline $\mathrm{C}$ & 17,4 & 36,2 & 28,0 & 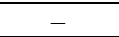 & 1,42 & 2,75 & 48,4 & 26,5 & 11,5 & 8,2 & 15,4 \\
\hline \multicolumn{12}{|c|}{ Iirrigated, 15 years } \\
\hline$A_{\max }$ & 12,9 & 37,9 & 25,3 & 28,0 & 1,18 & 2,65 & 55,5 & 24,7 & 9,7 & 9,3 & 26,3 \\
\hline $\mathrm{AB}$ & 18,7 & 41,3 & 28,1 & 31,9 & 1,33 & 2,66 & 50,0 & 24,8 & 2,8 & 9,5 & 21,3 \\
\hline $\mathrm{B}$ & 19,6 & 39,2 & 26,7 & 78,0 & 1,29 & 2,70 & 52,2 & 30,5 & 15,5 & 9,1 & 16,8 \\
\hline $\mathrm{BC}$ & 19,0 & 37,6 & 25,6 & - & 1,47 & 2,71 & 45,7 & 23,7 & 8,7 & 8,7 & 15,0 \\
\hline $\mathrm{C}$ & 16,0 & 37,2 & 30,0 & - & 1,51 & 2,71 & 44,1 & 23,8 & 10,3 & 8,3 & 13,4 \\
\hline \multicolumn{12}{|c|}{ Iirrigated, 30 years } \\
\hline $\mathrm{A}_{\max }$ & 15,0 & 39,1 & 28,2 & 19,5 & 1,10 & 2,63 & 58,2 & 25,0 & 10,0 & 9,4 & 27,4 \\
\hline $\mathrm{AB}$ & 18,2 & 40,6 & 27,4 & 37,9 & 1,22 & 2,66 & 54,1 & 22,9 & 7,9 & 9,5 & 21,0 \\
\hline B & 19,6 & 40,6 & 25,7 & 82,2 & 1,25 & 2,69 & 53,5 & 25,6 & 15,6 & 9,2 & 17,9 \\
\hline $\mathrm{BC}_{\mathrm{K}}$ & 17,9 & 38,5 & 26,7 & - & 1,31 & 2,72 & 51,8 & 28,2 & 4,8 & 8,8 & 18,0 \\
\hline $\mathrm{C}_{\mathrm{K}}$ & 17,0 & 37,6 & 29,7 & - & 1,47 & 2,72 & 46,0 & 24,0 & 9,0 & 8,5 & 15,0 \\
\hline
\end{tabular}

Humus is dark brown (almost black) in non-irrigated chernozem, which turns brown, light brown in irrigated. In the upper horizons of the profile, there are iron-humus concretions; in the illuvial horizon their number increases sharply. In the upper horizons, the deferrization of clay plasma occurs, in the lower horizons - the redistribution of carbonates.

All data indicate the development of leaching processes and temporary waterlogging, which is recorded by a decrease in ORP in the post-irrigation period. Under the influence of these processes, there is a migration of ferrous-humic substances, loss of calcium and carbonates, leading to a change in the micro- and macro-aggregate composition (Table 2 ). Changes are manifested in increasing the mechanical strength of the aggregates, their density. A similar phenomenon is observed in the first 15 years of irrigation. Longer (30 years) irrigation is accompanied by a decrease in the mechanical strength and density of soil aggregates. At the same time, in the arable horizon, the number of waterintensive aggregates of size $5-0.25 \mathrm{~mm}$ decreases. As irrigation continues in the illuvial horizon, where accumulation of humus and iron is detected, the number of water-resistant aggregates increases. In the subsurface horizon, in the first years of irrigation, the structure was destroyed, in subsequent years there was a steady tendency for aggregates to accumulate, although a decrease in the mechanical strength and density of the aggregates indicates the beginning of disaggregation processes in irrigated chernozems for a long time. In this regard, we should expect the consolidation of the upper horizons. In general, the profile of the long-irrigated chernozem remained looser than the chernozems irrigated for a shorter time. In the cultivation of perennial grasses, the density of irrigated chernozems is much higher than that of non-irrigated ones. 
Other physical properties under the influence of irrigation with non-mineralized waters in the conditions of vegetable crop rotation have changed slightly.

The transformation of the physical condition of chernozems southern, which are also irrigated by the nonmineralized waters of the $\mathrm{r}$. Aley (total mineralization not more than $0.3 \mathrm{~g} / \mathrm{l})$. Continuous irrigation of chernozems on large areas, elevated $(3000-4000 \mathrm{~m} / \mathrm{ha})$ irrigation rates and due to high infiltration water losses through the earthen bottom of irrigation canals - led to an increase in the level of saline (sulphate type) groundwater and salinization of irrigated chernozem and meadow-chernozemics soils.

In the first 10 years of irrigation, until the groundwater reached a critical level and had no effect on irrigated chernozems, soil formation was accompanied by the removal of readily soluble salts, a decrease in the cation exchange capacity, an increase in the mobility of humic substances, iron. The change in physical condition was under the control of these processes. The result of transformation of a physical state was analogous to that which we observed in chernozems leached of the kolochnaya steppe (irrigated with waters of the same quality as in r. Aley).

These changes were accompanied by the formation of a dense angular, mechanically water-resistant structure, compaction of the profile, a decrease in total porosity, air capacity, and an increase in water-holding capacity.

In all irrigated soils irrespective of the mechanism of transformation, a reduction of water penetration is observed. In reduction of filtration is long the irrigated boggy southern chernozems are insignificant. The last is probably explained by the fact that in this case calcium, magnesium, iron, organic substance remain on the place, supporting in some balance the soil structure, and, therefore, a certain water penetration.

The results obtained allow us to recognize that irrigation with not mineral and mineral water leads to a transformation of the physical state. Both in this and in other cases, the processes leading to the differentiation of the profile according to the eluvial-illuvial type prevail. During irrigation with fresh water (less than $0.3 \mathrm{~g} / 1$ of salts), apparently, the change in physical properties is associated with the manifestation of the podzolization process (a witness of the process of a decrease in $\mathrm{pH}$ ). Under local irrigation with sulphate waters in chestnut soils, the change in physical condition is due to the process of solonetzation (and possibly solodization). In the southern chernozems, the degradation of the physical state at the initial stage of irrigation was influenced by leaching processes, and after the rise of saline groundwater, the change in the physical state occurs under the control of solonetzation-salinization processes. Such transformation of irrigated lands affects the level of food security of the study area, as they deteriorate; resistance to anthropogenic influences decreases, which affects crop yields.

\section{V.CONCLUSION}

To eliminate the negative effects of local irrigation of chestnut soils and chernozems in the South of Western Siberia and to improve the food security of the region, a set of measures is recommended that has been tested for six years on leached chernozem of medium-power low-humus medium with loamy granulometric composition.

The complex provides the following:

1) construction of irrigation systems with the closed water distribution network excluding irrigation water losses;

2) anti-erosion measures: planning, deep loosening, bringing the intensity of artificial rain in line with the absorption capacity of the soil;

3) to prevent soil salinization, it is necessary to introduce chemical meliorants (gypsum, phosphogypsum, etc.): the norm of reclamation substance depending on the quality of irrigation water varies from 1-2 to $8-12 \mathrm{t} / \mathrm{ha}$ of the crop rotation area;

4) the use of fodder crop rotations (5-6 types), in which alfalfa has been cultivated for 3 years and a positive humus balance is ensured;

5) wetting no deeper than $40-80 \mathrm{~cm}$ at an acceptable lower limit of humidity of $65-70 \% \mathrm{HB}$ and irrigation rate of $350-400 \mathrm{~m} / \mathrm{ha}$.

The complex of measures allows one to obtain an average of 60-65 t/ha of green corn mass, 10-13 t / ha of alfalfa hay without a significant reduction in the fertility of irrigated agrosoils. At the same time, it is necessary to organize monitoring of irrigated lands.

\section{References}

[1] I.N. Antipov-Karataev, V.I. Filippova, The effect of long-term irrigation on the soil, Moscow: Publishing House of the Academy of Sciences of the USSR, 1955.

[2] A.P. Biryukova, The influence of irrigation on water and salt regimes of the soils of the Southern Volga region, Moscow: Publishing House of the Academy of Sciences of the USSR, 1962.

[3] V.A. Baranovskaya, V.I. Azovtsev, "The influence of irrigation on the modern soil-forming process", Moscow: Publishing House of the Academy of Sciences of the USSR, 1974, pp. 132-142 [X Intern. congress of soil scientists, 1974]

[4] V.A. Kovda, "Problems of combating desertification and salinization of irrigated soils", Moscow: Kolos, 1984.

[5] V.A. Kovda, V.V. Egorov, "Old and new problems of Soil Reclamation in the Irrigation Zone", Soil Science, 1972, vol. 4, pp. 3-9.

[6] B.G. Rozanov, "Forecast of the evolution of chernozems in the south of the European part of the USSR under irrigation", Moscow: Publishing House of Moscow State University, 1975, pp. 65-75 [Problems of the genesis and melioration of irrigated soils, 1975]

[7] N.G. Minashina, Reclamation of saline soils. Moscow: Kolos, 1973.

[8] Aydarov I.P., Korolkov A.I. Irrigation of Chernozem, Hydrotechnics and Land Reclamation, 1984, vol. 12, pp. 23-34.

[9] V.E. Prikhodko, A.N. Galibin, I.V. Ivanov, "The influence of irrigation on the properties of dark chestnut soils of the Syrt plain of the Volga region", Soil Science, 1986, vol. 5, pp. 76-86.

[10] K.Y. Fesko, Irrigation regime and land reclamation issues AOC: Author's abstract, Diss. for Dr. of agricultural sciences, Novocherkassk, 1973.

[11] Panfilov V.P. Physical properties and water regime of the Kulunda steppe soils. - Novosibirsk: Science SO, 1973.

[12] Soil-physical conditions of land reclamation in Western Siberia. Novosibirsk: Science SB, 1977. 
[13] Chernozems: properties and characteristics of irrigation, Novosibirsk: Science SO, 1988

[14] L.P. Kozleneeva, Influence of irrigation with low-mineralized waters on the properties of Baraba chernozem plants: Author's abstract. Diss for Cand. Of biol. Sciences, Novosibirsk, 1988.

[15] L.M. Burlakova, L.M. Tatarintsev, "Reproduction of fertility of irrigated soils of the Altai Territory and ways of regulating the balance of humus", Pushchino, 1988, pp. 68-70. [All-Union Conference Soilagrochemical and environmental problems of the formation of highly productive agrocenoses, 1988].

[16] L.M. Burlakova, L.M. Tatarintsev, "The effect of irrigation on the chernozem and chestnut soils of the Altai Territory", 14-18 Aug. 1989, Novosibirsk, Novosibirsk, 1989, pp. 84-89. [VIII All-Union. congress of soil scientists, 1989]

[17] L.M. Tatarintsev, "The influence of irrigation on the chernozem properties of southern and dark chestnut soils of Kulunda and ways to prevent negative consequences during irrigation of Siberian soils", Aug 10-12 1980, Abakan, 1988, pp. 33-35.
[18] L.M. Tatarintsev, L.M. Burlakova, N.K. Glushkova et al, "Fertility of chernozems of the Altai Ob on irrigation", In Development and use of reclaimed land and water resources in the south of Western Siberia, Barnaul: Altai Agricultural Institute, 1989, pp. 34-45.

[19] L.M. Tatarintsev, L.M. Burlakova, A.E. Kudryavtsev, "Evolution of chernozems of the Altai Priobye during irrigation", In Soil science, lithogenesis and paleogeography, Tomsk, 1991, pp. 51-53.

[20] L.M. Tatarintsev, V.L. Tatarintsev, T.I. Pushkarev, "Change of ameliorative state of chestnut soils of dry steppe during irrigation", Bulletin of the Altai State Agrarian University, 2012, vol. 9 (95), pp. 2529

[21] V.L. Tatarintsev, L.M. Tatarintsev, "Salt accumulation in the soils of the Altai Kulunda depending on the structure of the particle size distribution", Bulletin of the Altai State Agrarian University, 2016, vol. 2 (136), pp. 50-58. 